\title{
Spanish and Catalan in the Balearic Islands
}

\author{
JOSÉ LUIS BLAS-ARROYO
}

\section{Abstract}

The Balearic Islands are one of the autonomous regions of modern Spain, where both Catalan and Spanish are considered official languages and are widely spoken among the population. Historically, the main language of the region has been Catalan, brought to the islands during the Spanish Reconquest from thirteenth century onwards. The presence of Spanish was noted much later, as a slow language substitution process starting in the sixteenth century took place. This article analyzes the functional distribution of both languages today, as well as consequences of secular language contact and some attitudinal aspects of Balearic social bilingualism.

\section{Introduction: the demographic and social context ${ }^{1}$}

Just like other autonomous regions in Spain today, the Balearic Islands are subject to the Statute of Autonomy passed by the Regional Parliament in 1983. The region is ruled by a general government, although the islands of Majorca, Minorca, and the Pitiusas archipelago have their own subsidiary councils.

The economy of the Balearic Islands has changed substantially over recent decades from mainly agricultural activities up to the first half of the nineteenth century to a completely different type of economy mainly based on the tertiary and construction sectors as a consequence of the massive tourism that started in the islands at the beginning of the 1960s. The special climatic conditions of the region, particularly mild in this part of the Mediterranean, its international image, which has improved over recent years, its social and economic stability, and the huge expansion of the building trade all account for the large number of tourists visiting the islands every year (eleven million). As a result, the Balearic Islands, with a per capita income and a gross domestic product among the highest in

0165-2516/07/0184-0079

(C) Walter de Gruyter
Int'l. J. Soc. Lang. 184 (2007), pp. 79-93 DOI 10.1515/IJSL.2007.015 
1 our country, are among the most prosperous autonomous regions in 2 Spain, clearly above the Spanish average. However, the impact of tourism 3 is not the same for all of the islands, and it is especially significant on the 4 coast of Majorca as well as on the island of Ibiza. Inland Majorca and the island of Minorca, on the other hand, have been kept somewhat aside from this intense tourist development. As we will see below, such differences are reflected in the linguistic situation of the islands.

Along with the spectacular growth referred to above, the expanding economy of the islands has also brought a considerable rise in population - it has doubled in the last four decades. Part of the reason for this considerable population boom is immigration, which in this part of Spain features some qualitative as well as quantitative peculiarities. The latest available data, for example, place the region among the first in the number of immigrants, not only in Spain but even in Europe (only Luxembourg has higher rates [Ramón 2004: 49]). Currently, 34\% of the Balearic population was born outside the region, and a high proportion of the remaining $66 \%$ are second generation immigrants, something which will have significant consequences on the region's linguistic distribution (Salvà Tomàs 2002: 4).

On the other hand, the Balearic Islands are a melting pot of people from different geographic, economic, and cultural origins. The highest ratio among them corresponds to immigrants from other parts of Spain, the vast majority of which come from non-Catalan-speaking regions, and thus speaks Spanish. According to data from the 2001 census, 241,000 residents of the Balearic Islands fall into this group. Nevertheless, a significant number of European citizens with high levels of income have settled on the islands, mainly from the 1990s onward. They have chosen the place as a particularly attractive spot either to establish their residence after retirement or to set up a tourism-related business. A little over 100,000 people fall into this category $(105,742)$, among which the British and, particularly, the German communities stand out. Finally, the recent south-north waves of immigrants, drawn by the desire to find work or merely to survive, are made up of a growing number of people from Northern Africa $(28,756)$, closely followed by South Americans.

As we shall see below, this population distribution has decisive consequences for the linguistic differences of the Balearic Islands.

\section{The current linguistic situation in the Balearic Islands}

Historically, the Balearic Islands fall within the Catalan linguistic area, as do other eastern regions of the Spanish Peninsula, such as Catalonia 
or the Valencian Community. Traditionally, Catalan has been the main means of oral communication since the Reconquest. The presence of Spanish, on the other hand, was noted much later, and until recent times its use was clearly restricted to an ordinary means of communication. As a consequence of a language substitution process, extraordinarily accelerated during Franco's regime, the linguistic situation of the islands for decades has been considered as diglossic; one language, Catalan, was largely used by the majority of the population, though only in informal spheres, and Spanish was considered the cultivated language, useful therefore for more formal and prestigious situations.

After the fall of Franco's regime and the beginning of Spanish democracy, a social process of normalization of Catalan began, and it has become the "official" language, together with Spanish, of the Community in its Statute of Autonomy. This situation is similar to that of other regions with another language other than Spanish. After two decades of linguistic policy, this process has led to some progress. The level of knowledge of the native language shows significant improvement, particularly in the field of writing. Therefore, whereas in 1991 only $25.9 \%$ of the Balearic residents acknowledged that they knew how to write in Catalan, this figure increased to $31.1 \%$ in 1998 , and to a considerable $51.3 \%$ four years later, a noticeable increase helped by the presence of Catalan in the Balearic school system (Melià 2002: 61). Meanwhile, written competence in Spanish is almost universal. The progress of Catalan in other fields not so directly related to the measures taken in language policy is less spectacular, yet equally positive, at least in a more superficial and quantitative aspect. Accordingly, from $66.7 \%$ of the Balearic population who declared that they spoke Catalan at the beginning of the 1990s one of the highest figures of all the Spanish Communities with languages other than Spanish at the time - this figure increased ten percent to $76.7 \%$ in 2002 . Despite the most pessimistic predictions, this clearly demonstrates that there is a moderate advance of Catalan in the Balearic society, which is even more significant if we take into consideration the adverse circumstances in which the linguistic map of the islands fits.

Nonetheless, it is true that the distribution of such levels of knowledge differs considerably according to variables such as the speakers' birth place or their place of residence. In regards to the first variable, for example, out of the slightly more than half a million residents born on the islands, in 2002 nearly all of them $(95.9 \%)$ declare their ability to speak in Catalan ("well" or "not too badly"). This percentage, however, goes down to $47.2 \%$ among the immigrants born outside the islands (according to writing ratios, they are at $68.6 \%$ and $24.7 \%$ respectively [Melià 2002 : 
1 61]). Immigrants' lack of interest to assimilate the language, not only 2 Catalan but also Spanish in some cases, is outstanding and can be espe3 cially observed in the largest immigrant community, that of the Germans $4 \quad$ (58\% of them acknowledge that they speak neither Spanish nor Catalan). 5 On the other hand, the linguistic distribution varies, though to a lesser ex6 tent, depending on the island, and, within these, depending on the type of 7 town. Hence, the highest use of Spanish - and thus the lowest use of 8 Catalan - is seen on the island of Ibiza, as well as in the city of Palma 9 de Mallorca and in other coastal cities that have had important tourist development. The use of Catalan is widely spread in Minorca, as well as in inland Majorca (see more details about the use of languages by domains in Section 5).

\section{Historical presence of Spanish and Catalan in these territories}

As previously mentioned, the Balearic Islands belong to the group of Catalan linguistic regions of Spain. The presence of Catalan in the territory dates back to the thirteenth century when the King of Aragon, Jaime I the Conqueror, landed in Majorca (1229), and occupied the island of Ibiza shortly afterwards (1236). It was not until 60 years later that the conquest of Minorca took place (1287). Minorca had previously been one of the small states that remained after the collapse of the Caliphate of Cordoba and paid homage and fealty to the Christian King. The fact that all this land was repopulated with people from the Catalan-speaking eastern regions of Rosellón, Gerona, and Barcelona explains why the Balearic inhabitants then started speaking Catalan in its eastern variety, and continued doing so for many centuries.

As far as the linguistic history of Majorca is concerned, several periods have been identified that account for the process of substitution of Catalan by Spanish (Miralles i Monserrat 1989: $111 \mathrm{ff}$.). During the three centuries that followed the conquest of the island, Catalan was the main language of the territory with certain scarce traces of language contact with Latin, the main culture language, as well as with the language spoken by some ethnolinguistic minorities like Arabic - a culture language of the previous settlers of Majorca - Hebrew, Langue d'Oc, or Aragonese. Conversely, language historians maintain that Spanish was practically unknown on the island until the end of the fifteenth century, although some Spanish texts began to be translated into Catalan over the course of the century. Decisive influences on the evolution of the standard variety of Catalan during medieval times were Ramon Lull's 
philosophical works and the use of this language in the Royal Chancellery of Majorca.

Miralles i Monserrat (1989: 120) sets the beginning of the substitution process in the two centuries stretching from King Ferdinand the Catholic's death to the signature of the Ordinance of New Plant (Decretos de Nueva Planta) at the beginning of the eighteenth century. During this period of Decadence (Decadencia), Spanish began to penetrate into these lands first by means of writers, and later, through members of the aristocracy and the high clergy, many of whom came from non-Catalanspeaking regions of Spain (the introduction of the Spanish Inquisition to the Balearic lands in 1488 also played an important part in the process of the Spanish supremacy of the islands). During this same period, however, Catalan would continue to be the only vehicle of oral communication among the natives, as well as the main language (sometimes the only one) of the religious sphere.

The true starting point of this linguistic substitution would be at the beginning of the eighteenth century with the aforementioned Decretos de Nueva Planta, established by the Bourbon monarchy after the War of Spanish Succession. These absolutely centralist decrees were opposed to the maintenance of native languages or cultures in Spanish territories. The Spanish-over-Catalan substitution process "through the judicial and administrative channels" led to a use of Spanish in mainly official domains, such as administration, justice, entertainment (theatre), etc., areas that had been traditionally reserved for Catalan. In the "hispanization" process of these territories, once again eminent representatives of the state administration and the ecclesiastical hierarchy would play an outstanding role. Additionally, a handful of members of the Enlightenment would also join in (with some remarkable exceptions, like Jovellanos). This, among other things, would explain why the first newspapers of the islands published between the eighteenth and nineteenth centuries would already be written in Spanish.

Nevertheless, and in spite of the fact that the substitution process would be prolonged over the next two centuries with its inevitable ups and downs, it was not until the second half of the twentieth century, with Franco's regime in full swing, that the most repressive policies against Catalan were witnessed. Up until then, the diglossic situation of the islands had kept the use of this language in the oral sphere, although reserved for the family and colloquial domains. However, while Franco remained in power, the correlation of forces began to change, particularly from the time economic development policies started, and several hundred thousand Spanish immigrants came to the Balearic Islands. Since then and until recently, Spanish, as the only officially acknowledged 
1 language, became inexorably associated with social and material progress, an idea which was particularly intense among the immigrants, who showed no interest whatsoever in adopting the native language or culture. At the same time, the difficulties of using Catalan in formal domains, such as education, local councils, or the administration of justice, would result in its being identified as a language used by uncultivated, poor people, something which was even believed by the Catalan speakers (see Section 5 below, relating to the present-day situation after the restoration of democracy in Spain).

\section{Linguistic description of Spanish in the bilingual areas: consequences of linguistic contacts}

Similar to what happens in other Catalan linguistic regions, the Spanish of the Balearic Islands exhibits some peculiarities owing to its contact with the local language. Following a well-known structuralist paradigm (see Weinreich 1953; Payrató 1985), these traits, which affect all analysis levels, can be classified through various interferential mechanisms (for further information, see Moll 1961; Serrano 1996-1997a, 19961997b):

a) UNDERESTIMATION of structural oppositions in certain paradigms of Spanish as a consequence of the influence of Catalan. This happens, for example, at a phonetic level with certain confusion affecting the unstressed vowels $[\mathrm{o}] /[\mathrm{u}] \rightarrow[\mathrm{u}] ;[\mathrm{a}] /[\mathrm{e}] \rightarrow[\mathrm{\partial}]-$, and the way these vowels are pronounced in the Eastern Catalan dialects. The same applies to consonantal phenomena, such as the Balearic seseo as a result of the neutralization of $[\mathrm{T}] /[\mathrm{s}] \rightarrow[\mathrm{s}]$ (cazar 'to hunt' $\rightarrow$ casar), since Catalan ignores the first of these phonemes. Likewise, its grammar shows some examples of the same type, such as the reduction to dual frames of paradigms that are composed of three elements in standard Spanish: for example, demonstratives: este / ese/aquel 'this/that (one)' $\rightarrow$ este/aquel (cat. aquest (aqueix)/aquell); aqui/ahi/alli(allá) 'here, there' $\rightarrow$ aquí/allí (cat. ací(aquí)/allà); cada/ todo 'each/whole' $\rightarrow$ cada (cat. cada). Finally, the same underestimation processes occur in specific vocabulary fields where the lack of certain significant distinctions in Catalan leads to the use of a single term in the Spanish used on the islands. That is precisely what happens, for example, with the pairs traer/llevar 'to bring/to take' $\rightarrow$ llevar, sentir/oir 'to feel/ to hear' $\rightarrow$ sentir, tirar/echar 'to throw/to fire' $\rightarrow$ tirar, hacer daño/doler 'to hurt/to have a ...' $\rightarrow$ hacer daño, agradar/gustar 'to appeal/to like' $\rightarrow$ agradar, etc. This is due to the fact that when some dominant 
1 Catalan speakers are faced with the two options, they tend to choose the 2 first when speaking Spanish.

3 b) Overestimation, contrary to the previous process, implies mak4 ing certain structural distinctions that are not made in the standard 5 variety of Spanish, once again demonstrating the influence of the native language. For example, this process leads to the articulation of open and closed vowels in the Spanish spoken in the islands (the case of $/ \mathrm{o} /$ and $/ \mathrm{e} /$ ), as well as to the distinction between several variants in some grammatical units, such as the modal form como 'like or as' $\rightarrow$ como/como a/como que (cat. com/com a/com que). Some lexical items also show phenomena of the same type: trabajo 'work' $\rightarrow$ trabajo / faena: Su faena no le agrada 'He/she doesn't like his/her work', Hacía la faena de la escuela muy pronto 'He/she did his/her homework very soon'.

c) ReINTERPRETATION is a mechanism by means of which elements of Spanish are no longer opposed to themselves through patrimonial features, yet they become so by using Catalan characteristics. Although less frequent than others, it can also be noticed in certain grammar spheres, like in the semantic reorganization of some verbal periphrasis (deber, tener que 'have to' [obligation] / deber de 'must be' [probability] $\rightarrow$ haber de, tener de 'have to' [obligation] / deber 'must be' [probability]) and prepositions ( $a$ 'to' [movement] / en 'in' [position] $\rightarrow$ en 'movement' / $a$ 'position': Fuimos en Palma 'We went to Palma', Está a casa (de) la abuela ' $\mathrm{He} / \mathrm{she}$ is at his/her grandmother's house'). The same thing occurs with certain lexical pairs the meaning of which varies slightly from standard Spanish: ir/venir 'to go/to come' $\rightarrow$ venir/ir: Mañana vendré $\underline{a}$ Palma 'I will go to Palma tomorrow', ; Ya vengo! 'I'm coming!'.

d) The IMPORTATION process implies the simple transfer of characteristic Catalan features that are absent in the equivalent Spanish paradigms. An example of this is observed in the presence of $d e$ with partitive values (Se coge tres o las que se quiere poner de patatas ' $\mathrm{He} / \mathrm{she}$ takes three potatoes or the quantity he/she wants') or as introductory form of complements with certain verbs (Mis hermanos me enseñaron de ir en bici 'My brothers showed me how to ride a bicycle'). Additionally, in this section we could also include some lexical catalanismos ('Catalan words') frequently used in Spanish by the islanders.

e) Finally, there are some cases of substitution of equivalent units in both languages that affect the Spanish spoken on the Balearic Islands. In pronunciation, for example, the principle of linguistic economy leads to a replacement of certain sounds by others that are closer to the Catalan phonetics. This happens with the articulation of /d/ at the end of a word, marked in these territories by a particular tension (verdad $\rightarrow$ verdat), or 
1 that affecting the lateral consonant $/ 1 /$, pronounced with a characteristic velar feature $($ fatal $\rightarrow$ fatal) $)$. A similar process occurs in some cases of confusion between verb tenses in certain syntactic structures, such as time clauses, where the norm imposes the subjunctive rather than the future indicative. The latter, however, is characteristic in the speech heard in these regions (Cuando llegará, le haremos una fiesta 'When he/she will come, we will give him/her a big party' vs. stand. Cuando llegue, le haremos una fiesta 'When he/she comes, we will give him/her a big party') or the frequent substitution of the standard Spanish obligation periphrasis (tener que 'have to') by a Catalan one of an interferential nature (tener de 'have to').

\section{Use of the languages by domains}

The data we have available on linguistic uses in different social domains shows some tentative signs of evolution in the linguistic normalization process that has been established over the last two decades. After comparing several recent surveys on the use of the two languages on the Balearic Islands, Melià (2002), for example, observed how in some domains where the use of Catalan has traditionally been more intense, the presence of this language has diminished clearly in favor of a more widespread bilingualism (random use of any of the two languages), and to a lesser extent, in favor of an exclusive use of Spanish. This occurs in the verbal interaction with one's friends or one's children, as the data in the following table displays.

Table 1. Use of Catalan and Spanish in two different social environments (\%) (our own elaboration from the data of Melià [2002: 63])

\begin{tabular}{lcl}
\hline & $1998(\%)$ & $2002(\%)$ \\
\hline With friends & & \\
$\quad$ More often in Catalan & 61.4 & 43.4 \\
In both languages alike & 17.4 & 30.4 \\
More often in Spanish & 21.2 & 25.9 \\
With children & & \\
More often in Catalan & 72.8 & 55.8 \\
In both languages alike & 8.3 & 15 \\
More often in Spanish & 18 & 28.7 \\
\hline
\end{tabular}

In other domains, differences are even slighter, where the rates of use between Spanish and Catalan are very close in the communication between 
couples, at work, or in public, shown as $40.5 / 49.9 \%, 29.6 / 31.7 \%$, and $25.5 / 33.4 \%$, respectively. In these last two, the most frequent communication scheme takes place in either language by changing from one language to the other according to certain communication factors, among which the speaker's linguistic adscription is especially relevant. The rates for this communication scheme in either language in both social domains are $38.5 \%$ and $41 \%$, respectively. Even so, the linguistic accommodation to the speaker's language is greater among the Catalan speakers than among the Spanish ones, who are generally more reluctant to resort to Catalan when they address their Catalan counterparts. This tendency also occurs in other Catalan-speaking territories. In short, it seems that this bilingual model of communication is becoming more and more popular among the Balearic population, as opposed to linguistic fidelity to a certain language.

Again, there is a considerable difference in these uses among native speakers (born on the islands), as they are understandably more inclined to use their language, whereas most immigrants are more likely to resort to Spanish. However, the data from these surveys also allows us to notice how a significant number of people, whose mother tongue is not Catalan, is beginning to use this language in non-family relationships on a regular basis, a positively-viewed fact in the linguistic normalization process taking place among speech communities with large immigrant populations (Melià 2002: 63).

Spanish is favored in the public and institutional fields, though it should be pointed out that the promulgation of the Law of Linguistic Normalization in 1986 has brought about some important advances for the native language. Despite the presence of Catalan in both compulsory as well as university education, not only as a compulsory subject but also as an educational instrument (see Section 7 below), Catalan has become widespread at the expense of Spanish in some spheres of public administration, particularly again in the more Catalan-speaking regions of Minorca and Majorca. Nevertheless, the political changes made in recent years have led to the establishment of some contradictory political measures that support two different positions. On the one hand, there are those who support the social normalization of the autochthonous language by considering Catalan as the main public and institutional language. Indeed there are those who even think it should be the only official - language. On the other hand, there are those who endorse a general process of bilingualism in the Balearic society with a nondiscriminatory use of both languages. Leading the first position during the period 2000-2004 was the so-called Entesa de Progrès, a coalition between the Socialist Party of the Balearic Islands and some nationalistic 
1 parties. This government carried out some language policies which particularly favored Catalan, such as the requirement of certain levels of competence in this language to gain access to the Civil Service. In that same period and from 2004, the conservative and regionalist Popular Party has held back some of these measures since it believes that they threaten social bilingualism.

As a result of these conflicting policies, the measures adopted by the different governments regarding the public media are equally opposed. For this reason, an intense controversy exists in the Balearic society as to which language should be used in the programs of the future autonomous TV, a third public TV channel authorized many years ago, but which is still to be put into practice. In this sense, the Balearic Islands differ from other Catalan-speaking regions, such as Catalonia or the Valencian Community, which have their own autonomous channels that are, however, seen in the Balearic Islands thanks to the initiative of some cultural institutions. As for the future Balearic channel, the nationalist sectors defend a channel that is entirely televised in Catalan, like the Catalan TV3, whereas the non-nationalist parties want a bilingual channel similar to the Valencian Canal 9, where programs alternate in both languages, something which they believe is more appropriate to the Balearic linguistic reality.

All things considered, and with some already mentioned exceptions, both the public and private television channels presently watched in the islands broadcast their programs in Spanish. A similar situation can be found in the radio and the press, as both forms of media are still mainly dominated by Spanish. The local newspapers, for example, are mainly written in Spanish, with the occasional article or partial supplement in Catalan. The only exception in recent years has been the Diari de Balears, written entirely in Catalan, as well as some weekly magazines published by the Associació de la Premsa Forana de Mallorca.

Finally, both stances on language distribution in the islands are reflected in the entertainment business, cinema, and theatres. Therefore, while the seventh art is seen almost entirely in Spanish with a few exceptions sponsored by the autonomous governments, theatre is mostly performed in Catalan.

\section{Linguistic attitudes}

The data available on linguistic attitudes shows some signs of collective identity that are barely related to the characteristic, nationalistic spirit 
of other neighboring communities (Catalonia), or even to the linguistic affiliation of the people themselves. In his study on the youth from Majorca, for instance, Melià (1997) states that almost 64\% of young people on the island prefer the adjective mallorquin to define themselves no matter what their mother tongue is. Work by Siguan (1999) on the relationship between the people's identity and their level of nationalism in the Spanish autonomous communities with their own languages seems to agree. When asked the question: "Should someone speak the native language to be considered Balearic?", only $32 \%$ of those interviewed answered affirmatively, a low percentage that has only been surpassed by the even less frequent reply regarding the need to "have nationalistic feelings" (24\%). Nevertheless, contrarily, "having been born in this Autonomous Community" (53\%), "living and working in this Community" $(48 \%)$, and above all "being willing to belong to the Community" $(83 \%)$ are the most widespread opinions in the Balearic society. Additionally, once again the rates of diverse identity show a tendency to the "happy medium," as can be seen in the fact that the majority of people $(52 \%)$ consider themselves to be "Spanish as well as Balearic," whereas only $21 \%$ of them feel they mainly belong "to their Autonomous Community," or $24 \%$ regard themselves as only "Spanish." These figures are in marked contrast to those of other historical communities, such as Catalonia or the Basque Country, where nationalistic feelings are much more intense.

This same tendency to moderation and to avoid drastic changes in their linguistic policies has also been observed in other studies like the abovementioned study by Melià (1997). This author has observed, for example, that as part of their strategy to avoid the language conflict, school children from Majorca use accommodation strategies towards the speaker's language, although this tendency is significantly more frequent among Catalan speakers. Even passive bilingualism is favorably viewed by these youths, who regard it as a communication form in which each speaker uses his/her favorite language.

Nevertheless, while "speaking Catalan" is not regarded as the main identity sign by the majority of Balearic people, the linguistic normalization process of this language has increased its value as a means of communication. This is particularly true even for the Spanish speakers, who, in order to find a job on the islands, sometimes value the necessity to know Catalan even more than the Catalan speakers do. Consequently, for example, the use of Catalan and Spanish in education is viewed positively by schoolchildren and parents alike since they consider this as a useful instrument in the material progress of individuals in contemporary Balearic society. In contrast, only a minority of the population 
1 would prefer to have an education entirely in Spanish or entirely in 2 Catalan.

3 Meanwhile, the more general the questions asked are, the more pos4 itive the opinions given regarding the native language become, but these positive feelings diminish significantly when they have a direct effect on people's daily lives. All in all, these "politically correct" opinions, so characteristic of the periods of social normalization of a language, and which few are able to avoid, do not square with the real use of the language in most cases. In practice, some recent studies on language attitudes using indirect techniques have even questioned the reality of some of these assessments. This is what Pieras-Guasp (2002) has recently observed when comparing the results obtained with questionnaires and the "matched-guise" technique in different parameters related to social status and solidarity. According to the latter technique, and contrary to what is observed when informants are directly asked about languages, a majority of young people still see Spanish, rather than Catalan, as the most important means of communication, social mobility, and power. In contrast, Catalan is better valued in terms of solidarity but only, and again this aspect is important, by its speakers and not by Spanish speakers. As the author of the study points out: "For the students, knowing the two languages (that is, Catalan in addition to, not instead of, Spanish) can be useful in passing compulsory courses at school and in being better equipped to find a job. Spanish is still the language associated with power, economic well-being and prestige" (Pieras-Guasp 2002: $63)$.

\section{Teaching of and in Spanish and Catalan in school and at university}

After years of education in either only or mainly Spanish (during Franco's regime), the Balearic Islands' education system has not only established the teaching of the two languages, but also their use as a means of communication in school. Following the difficulties entailed by the late concession of autonomous competences in education (during the academic year 1997-1998), a decree of "minimal requirements" promulgated in 1997 by the Government of the Islands established that at least $50 \%$ of all school subjects were to be taught in Catalan, although no minimum limit was set for Spanish. The decree had to be enacted within a fouryear period and at least the subjects of science and social studies had to be taught in Catalan from the beginning. In any case, every school has to decide the use of both languages by means of its "linguistic project," 
which is presented by the staff and has to be approved by the school council. Until a decade ago, the percentage of students who received their education entirely in Catalan amounted to $20.7 \%$, whereas $63 \%$ did so in Spanish, and the remaining $16.2 \%$ were taught in bilingual programs (data for the academic year 1993-1994). More recently, and despite the fragmentation of the available data, things seem to have changed remarkably, above all in the four-year period 2000-2004, when the nationalistic government of the left-wing coalition Entesa de Progrès accelerated the generalized use of Catalan in the education system. According to the information provided by El Mundo newspaper, the number of nursery and primary education children (aged between three and twelve years of age) who studied all their subjects in Catalan rose from $49 \%$ to $62 \%$, a significant increase of $13 \%$ in the period ranging from the 1999-2000 to the 2002-2003 academic year. This has brought about some harsh criticism among certain sectors, who claim the right to choose the language their children are taught in, and these complaints have already been seen to by the new Popular Party government. Meanwhile, the situation varies considerably depending on the type of school (the use of Catalan is much more widespread in public schools than it is in private ones), and on the location of the centers (there is a large difference between the more Catalan-speaking areas of Minorca and inland Majorca, and the island of Ibiza, where, until recently, an overwhelming percentage of students were taught exclusively in Spanish).

Yet apart from the situation of social bilingualism, the islands presently face some additional linguistic problems, most of which are related to the presence of many foreign language minorities (up to 86 in 2004, according to the Dirección General de Politica Lingüistica). Evidently, these groups in which the students' mother tongue is neither Catalan nor Spanish increase the need for more compensatory education policies.

The university has been one of the main pillars of this process from the very beginning of the Catalan linguistic normalization. Therefore, Catalan is the official language of this institution, and all documents that are produced in its different departments are edited entirely in this language. The actual teaching offers a more balanced scenario since there is freedom of speech and language among teachers and students alike. Yet, significant differences prevail between some departments; the Art Department is one of the most revolutionary in the use of Catalan in its lectures, while Spanish is the main education language at the Law School and at some technical colleges.

University Jaume I, Castellón 


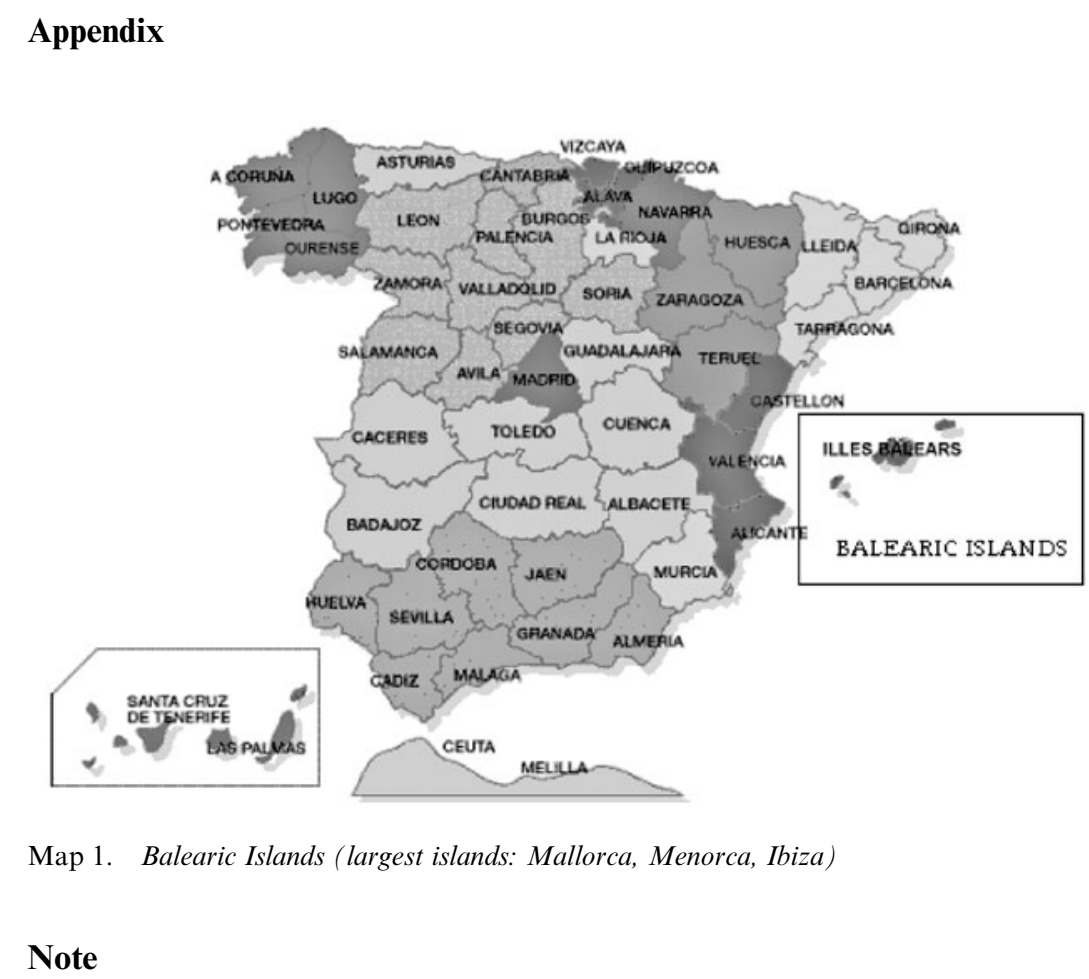

1. The Balearic Islands are comprised of two archipelagos located some $200 \mathrm{~km}$ from the eastern coast of the Iberian Peninsula in the Mediterranean Sea: the archipelago of Gimnesias, the Greek name given to the islands of Minorca, Majorca, and Cabrera, and that of Pitiusas, which includes the smaller islands of Ibiza, Formentera, and some of the surrounding islets. The islands, which comprise one of the autonomous regions of Spain, have a total land area of $4,992 \mathrm{~km}^{2}$. Seventy percent of the total population of 916,968 (2003) is concentrated on the largest island, Majorca, where the city of Palma, capital of the region and home of the local government, is located.

\section{References}

Melià, Joan (1997). La llengua dels joves. Palma de Mallorca: Universitat de les Illes Balears. -(2002). La situació lingüística a les Illes Balears: Comentaris al voltant d'una enquesta. Llengua i Ùs: Revista Tècnica de Politica Lingüistica 24, 61-64.

Miralles i Monserrat, J. (1989). La llengua catalana a Mallorca (1229-1986). In II Congrès Internacional de la Llengua Catalana, Vol. 8, II (ed.), 111-157. València: Institut de Filologia Valenciana.

Moll, Francesc B. de (1961). El castellano en Mallorca. In Homenaje ofrecido a Dámaso Alonso, Vol. II, III (ed.), 469-474. Madrid: Gredos. 
1

2

Payrató, Lluis (1985). La interferència lingüistica (Comentaris i exemples catalá castellá). Barcelona: Ed. Curial-Publicacions de l'Abadia de Montserrat.

Pieras-Guasp, Felip (2002). Direct vs. indirect attitude measurement and the planning of Catalan in Mallorca. Language Problems and Language Planning 26(1), 51-68.

Ramón (2004). IIII

Salvà Tomàs, Pere (2002). Les Illes Balears: un espai de cruïlla de fluxos immigratoris. Llengua i Ùs: Revista Tècnica de Politica Lingüística 24, 4-11.

Serrano, $M^{a}$ Carmen (1996-1997a). El castellano en contacto con el catalán en una comunidad escolar bilingüe. Anuario de Lingüística Hispánica 12, 1013-1021.

-(1996-1997b). Rasgos fonéticos de carácter interferencial en el castellano de una comunidad bilingüel. Estudios de Lingüística de la Universidad de Alicante 11, 365-383.

Siguan, Miquel (1999). Conocimiento y uso de las lenguas. Madrid: CIS.

Weinreich, Uriel (1953). Languages in Contact. The Hague: Mouton. 


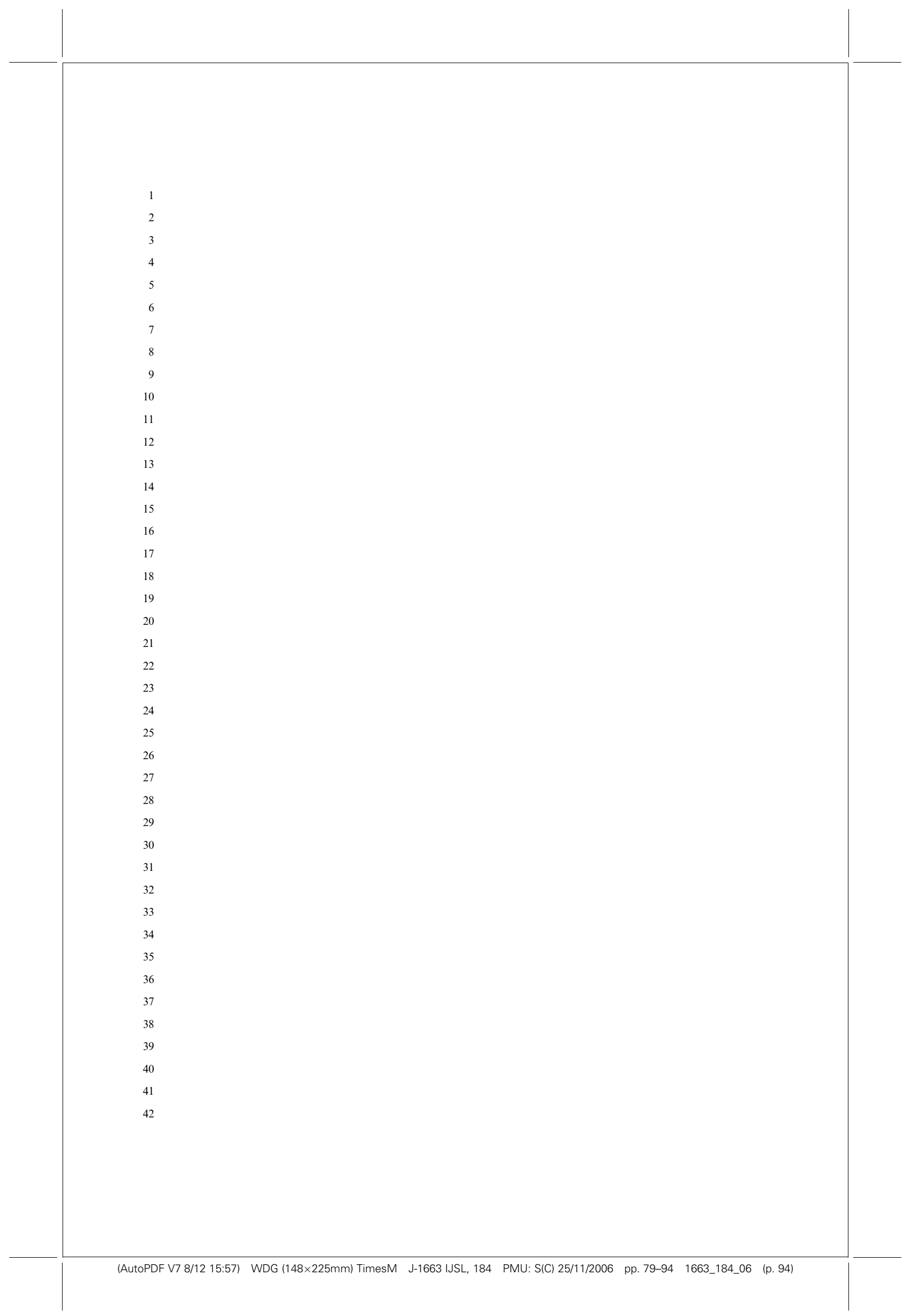

